\title{
ANALISIS KADAR LOGAM TIMBAL (Pb) PADA RAMBUT KARYAWAN SPBU
}

\author{
Dyna Putri Mayaserli, Renowati, M. Biomed \\ Sekolah Tinggi Ilmu Kesehatan Perintis Padang \\ Jalan Adinegoro KM 17 Simpang Kalumpang Padang \\ Email:dyna2205@yahoo.com
}

\begin{abstract}
Development in the field of health is the achievement of an optimal public health degree. Among people who are often exposed to air pollution such as lead metal $(\mathrm{Pb})$ is a gas station officer. One of the objectives of this research is to figure out the differences of lead level $(\mathrm{Pb})$ in the hair of SPBU workers who base on Jl. Ir. Juanda based on length of service period by using experimental research to analyze $\mathrm{Pb}$ metal at gas station workers. The population and sample of research is hair of three gas station workers that contains metal of lead $(\mathrm{Pb})$. The results of this study revealed that the longer employment period of workers, the higher the $\mathrm{Pb}$ level in their hair and the percentage recovery value for the wet destruction method using HNO3 and HCLO4 has an average recovery of $96.23 \%$ which is the precision test value of $4.01 \%$. It is recommended that the validation test then use another method of dry destruction and examine the identity of age, place of birth date and lifestyle.
\end{abstract}

Key words: Validation, Analysis Method, Metal Content $\mathrm{Pb}$

\section{PENDAHULUAN}

Udara bersih adalah udara yang cukup akan kebutuhan oksigen (O2) yang dibutuhkan makhluk hidup untuk proses fisiologis normal. Di daerah perkotaan yang ramai, gas pencemar berasal dari asap kendaraan, gas buangan pabrik, pembangkit tenaga listrik, asap rokok dan sebagainya yang erat hubungannya dengan aktivitas kehidupan manusia (Darmono, 2009).

Pembangunan di bidang teknologi dan industri berjalan sangat pesat. Pembangunan tersebut merupakan usaha untuk menyediakan sarana dan prasarana pendukung kesejahteraan manusia. Salah satu di antaranya adalah pertambahan sarana transportasi kendaraan bermotor. Pertambahan sarana transportasi memang memberikan dampak positif, namun ternyata juga memberikan dampak negatif karena dapat menurunkan kualitas lingkungan, salah satunya terjadi karena adanya emisi gas buang dari kendaraan berbahan bakar yang mengandung $\mathrm{Pb}$. Emisi gas buang merupakan hasil samping dari pembakaran yang terjadi dalam mesin-mesin kendaraan. $\mathrm{Pb}$ yang merupakan hasil samping dari pembakaran ini berasal dari senyawa tetrametil-Pb dan tetraetil$\mathrm{Pb}$ yang selalu ditambahkan dalam bahan bakar kendaraan bermotor dan berfungsi sebagai anti ketuk (anti-knock) pada mesin-mesin kendaraan (Heryando, 1994).

Emisi gas buang yang mengandung $\mathrm{Pb}$ jika dihirup oleh manusia akan menyebabkan keracunan sistemik. Menurut Slamet (1994) keracunan $\mathrm{Pb}$ akan menimbulkan gejala: rasa logam di mulut, garis hitam pada gusi, gangguan pencernakan, anoreksia, muntahmuntah, kolik encephalitis, wrist drop, iritasi, perubahan kepribadian, kelumpuhan dan kebutaan. Basophilic stippling dari sel darah merah merupakan gejala patognomonis bagi keracunan $\mathrm{Pb}$. Gejala lain dari keracunan ini 
berupa anemia dan albuminuria. Menurut Connel dan Miller (1995) $\mathrm{Pb}$ mempengaruhi pembentukan sel-sel darah dalam tulang belakang dan menghambat sintesis hemoglobin

Rambut manusia dapat menyerap unsur yang masuk kedalam tubuh manusia melalui makanan/pencernaan, pernapasan dan kulit. Keberadaan dan konsentrasi suatu unsur dalam rambut dapat merefleksikan keadaan/status kesehatan dimana seseorang tinggal dan bekerja. Pada Rambut gugus sulfhidril dan disulfida dalam rambut mampu mengikat unsur runut yang masuk ke dalam tubuh dan terikat di dalam rambut. Senyawa sulfida mudah terikat oleh unsur runut, maka bila unsur runut masuk ke dalam tubuh, unsur runut tersebut akan terikat oleh senyawa sulfida dalam rambut (Pettrucci, 1982). Dengan menganalisis unsur dalam rambut dapat diketahui apakah konsentrasi unsur tersebut kurang, cukup atau bahkan terlalu tinggi. Kelebihan melakukan analisis unsur dalam rambut jika dibandingkan dengan analisis unsur dalam darah atau urin adalah analisis unsur dalam rambut lebih mudah pelaksanaannya serta penanganan sampel lebih sederhana (Hidayat, 2008).

Orang yang sering terpapar oleh polusi udara salah satu di antaranya adalah petugas pom bensin. Diperkirakan emisi gas buang yang dikeluarkan dari kendaraan bermotor dapat menimbulkan kontaminasi terhadap tubuh para petugas pom bensin yang mengisi bahan bakar kendaraan. Menurut Darmono (1995) bahwa keracunan $\mathrm{Pb}$ pada orang dewasa biasanya terjadi di tempat mereka bekerja. Berdasarkan atas pertimbangan tersebut perlu dilakukan penelitian untuk Mengetahui perbedaan kadar $\mathrm{Pb}$ (timbal) dalam rambut pekerja SPBU di Jl. Ir. Juanda berdasarkan lama masa kerja

\section{METODE PENELITIAN}

Jenis penelitian ini adalah experimental laboratory dengan teknik pengambilan sampel systematic sampling dimana penulis ingin menggambarkan jumlah kandungan timbal dalam rambut pada pekerja SPBU di Jl. Ir. Juanda Populasi penelitian adalah pekerja
SPBU di di Jl. Ir. Juanda dengan jumlah 10 orang. Alat yang digunakan Spektrofotometer Serapan Atom, hot plate dan peralatan gelas. Bahan yang digunakan adalah rambut, standar $\mathrm{Pb}, \mathrm{HNO}_{3}, \mathrm{HClO}_{4}$, aquades.

\section{Proses Destruksi Basah}

Metode destruksi basah dengan menggunakan asam $\mathrm{HNO}_{3}$ dan $\mathrm{HClO}_{4}$ (Anonim. 1996) : potong segmen rambut sekitar 5 sampai $10 \mathrm{~mm}$ panjang dan berat $2 \mathrm{mg}$. Timbang sampel rambut dan cuci dengan aquades kemudian panaskan selama 15 menit dan didestruksi dengan campuran 1:5 $\mathrm{HClO}_{4}: \mathrm{HNO}_{3}$ hingga membentuk cairan hampir jernih. Encerkan sampel dalam labu ukur $50 \mathrm{~mL}$ dengan aquades hingga tanda batas. Kandungan logam $\mathrm{Pb}$ dalam rambut dapat dibaca dengan menggunakan AAS menggunakan lampu katoda $\mathrm{Pb}$ dengan panjang gelombang 283,3 nm Uji akurasi (ketepatan)

Uji ini dilakukan dengan cara menambahkan larutan baku pembanding $(\mathrm{Pb}$ $0.6 \mathrm{ppm}$ ) kedalam sampel yang akan diperiksa sebelum didestruksi, kemudian dilakukan uji blanko (tanpa penambahan larutan baku standar). Masing-masing sampel kemudian didestruksi dengan metode destruksi basah menggunakan $\mathrm{HNO}_{3}$ dan $\mathrm{HCLO}_{4}$ dan diukur menggunakan SSA pada panjang gelombang $480 \mathrm{~nm}$.

\section{Uji presisi}

Metode uji presisi dilakukan secara repatibilitas atau keterulangan dilakukan dalam kondisi yang sama dalam interval waktu yang singkat, yaitu dengan mengukur larutan sampel metode destruksi basah menggunakan $\mathrm{HNO}_{3}$ dan $\mathrm{HCLO}_{4}$ dengan 3 kali ulang pada hari yang sama, kemudian data hasil absorbsi dihitung simpang bakunya (Ervina, 2003).

\section{Uji Linearitas}

Uji ini dilakukan dengan membuat kurva kalibrasi standar dengan beberapa macam konsentrasi standar $\mathrm{Pb}$ yang dimulai dari larutan tanpa $\mathrm{Pb}$. Kemudian dilanjutkan dengan mengukur standar $\mathrm{Pb} 0.2,0.4,0.6,0.8$ dan 1 ppm. Setelah itu didapatkan harga "r" (Ervina, 2003). 
Uji Limit Deteksi (LoD) Dan Uji Limit Kuintitasi (LoQ)

Menurut (Ervina, 2003) uji LoD dan LoQ dapat diukur dengan konsentrasi standar yang paling rendah yang dapat terdeteksi absorbansinya dngan rumus :

LoD dapat dihitung dengan rumus :

$$
\text { LoD }=3 \times \text { SD }
$$

LoQ dapat dihitung dengan rumus : $\mathrm{LoQ}=10 \times \mathrm{SD}$

\section{HASIL DAN PEMBAHASAN}

Kadar Pb dalam Rambut dengan menggunakan metoda destruksi basah

Pada penelitian ini digunakan sampel rambut karyawan SPBU dengan berat sampel sebanyak 2 gr. Sampel tersebut didestruksi basah dengan menggunakan $\mathrm{HCLO}_{4}$ dan $\mathrm{HNO}_{3}$ diukur dengan SSA pada panjang gelobang $283.3 \mathrm{~nm}$. Fungsi dari destruksi adalah untuk memutuskan ikatan antara senyawa organik dengan logam yang akan dianalisis. Logam yang dianalisis adalah $\mathrm{Pb}$, kadar $\mathrm{Pb}$ dalam rambut merupakan salah satu indikator terkumulasinya logam $\mathrm{Pb}$ dalam tubuh. Salah satu syarat analisis logam dengan menggunakan SSA adalah sampel harus berupa larutan. Pelarut yang dapat digunakan untuk destruksi basah antara lain asam nitrat, asam sulfat, asam perklorat, dan asam klorida. Untuk itu dilakukan anlisis $\mathrm{Pb}$ dalam rambut dengan menggunakan metode destruksi basah dengan campuran asam yang berbeda (Apriyanto, A., 1989).

Tabel 1. Kadar Logam Pb Pada Rambut

\begin{tabular}{cccc}
\hline No & Lama Masa Kerja (tahun) & Jumlah Pekerja (orang) & Kadar Rata-Rata Pb $(\mathrm{mg} / \mathrm{g})$ \\
\hline 1 & $1-4$ & 3 & 0.3561 \\
2 & $5-8$ & 3 & 0.5918 \\
3 & $9-12$ & 4 & 0.8175 \\
\hline
\end{tabular}

Berdasarkan tabel 1 didapatkan kadar $\mathrm{Pb}$ dalam rambut karyawan SPBU. Semakin lama masa kerjanya semakin tinggi kadar $\mathrm{Pb}$ dalam rambut karyawan tersebut, karena lebih lama terpapar $\mathrm{Pb}$. Dari data diatas didapatkan hasil paling tinggi adalah $0.8175 \mathrm{mg} / \mathrm{g}$ dengan lama masa kerja 9-12 tahun.

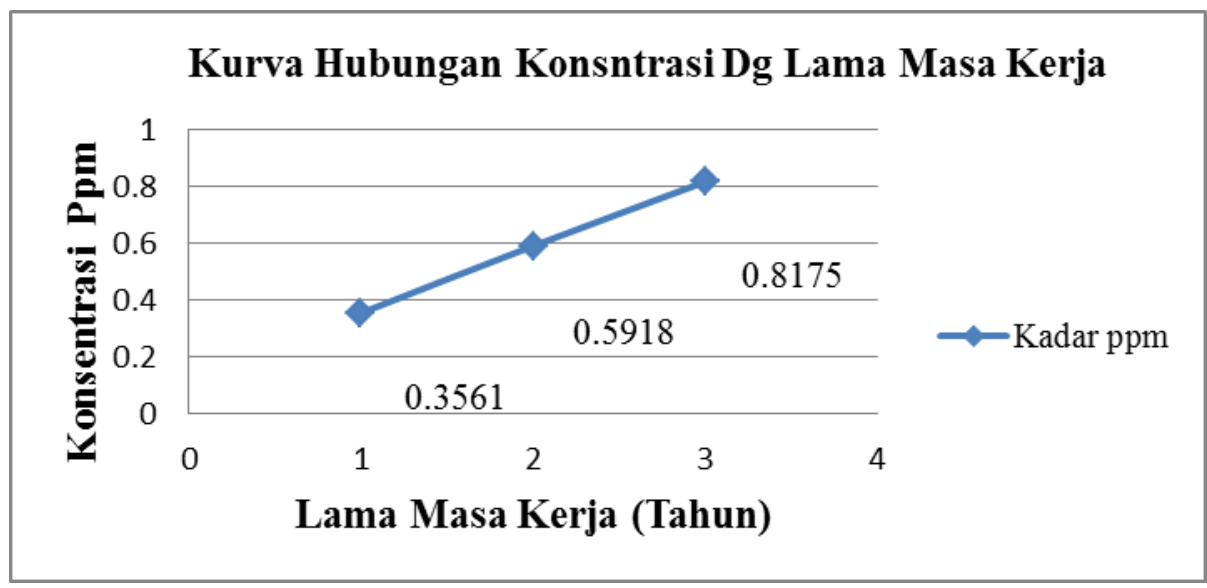

Gambar 1. kurva Kadar Logam Pb Pada Rambut (masa kerja 1: 1-4 2: 5-8 3: 9-12 tahun 
Pada grafik diatas bisa dilihat berdasarkan lama masa kerja karyawan SPBU bahwa semakin lama masa kerja karyawan SPBU semakin tinggi pula kadar logam $\mathrm{Pb}$. Timbal $(\mathrm{Pb})$ dapat masuk melalui pernapasan, makanan, dan minuman. Logam $\mathrm{Pb}$ dapat mempengaruhi sistem saraf, intelegensia, dan pertumbuhan. Efek logam $\mathrm{Pb}$ pada kesehatan manusia akan menimbulkan kerusakan otak, kejang bahkan kematian.

\section{Uji Akurasi (Ketepatan)}

Akurasi adalah ukuran yang menunjukan derajat kedekatan hasil analisa dengan kadar yang sebenarnya. Terkadang masalah dalam menentukan akurasi adalah ketidak tahuan terhadap nilai yang sebenarnya. Akurasi juga dapat diketahui dengan melakukan uji perolehan kembali (recovery) hasil uji ini akurasi dapat dinyatakan sebagai persen perolehan kembali (recovery) analit yang di tambahkan pada sampel. Akurasi dapat dilihat dari nilai recovery spike yaitu dengan cara menambahkan sejumlah analit (standar) yang diketahui konsentrsinya kedalam contoh. Ratarata dari nilai sebenarnya harus mendekati 100 $\%$, karena nilai kisaran persentase recovery disaratkan, yaitu $100 \% \quad \pm 15$ persentase recovery yang memenuhi persyaratan maka metode ini akurat (Ervina,2013)

Tabel 2. hasil uji recovery Logam Pb Pada Rambut

\begin{tabular}{cccccc}
\hline $\begin{array}{c}\text { Sampel } \\
(\mu \mathrm{g} / \mathrm{ml})\end{array}$ & $\begin{array}{c}\text { Volume Sampel } \\
(\mathrm{ml})\end{array}$ & $\begin{array}{c}\text { Spike Pb } \\
(\mu \mathrm{g})\end{array}$ & $\begin{array}{c}\text { Kadar Pb } \\
\text { Teoritis }(\mu \mathrm{g})\end{array}$ & $\begin{array}{c}\text { Kadar Pb } \\
\text { Analisis }(\mu \mathrm{g})\end{array}$ & $\begin{array}{c}\text { Recovery } \\
(\%)\end{array}$ \\
\hline $\mathrm{A}$ & 10 & - & - & 6.43 & - \\
$\mathrm{A}+2 \mathrm{ml} \mathrm{Pb} 0.6$ & 10 & 1.2 & 7.63 & 6.82 & 89.38 \\
$\mathrm{~A}+2 \mathrm{ml} \mathrm{Pb} \mathrm{0.6}$ & 10 & 1.2 & 7.63 & 6.68 & 87.5 \\
$\mathrm{~A}+2 \mathrm{ml} \mathrm{Pb} \mathrm{0.6}$ & 10 & 1.2 & 7.63 & 8.53 & 111.8 \\
\hline \multicolumn{7}{c}{ Rata-rata destruksi } \\
\hline
\end{tabular}

Berdasarkan tabel 2 diperoleh nilai persentase recovery untuk metoda dekstruksi basah dengan menggunakan $\mathrm{HNO}_{3}$ dan $\mathrm{HClO}_{4}$ mempunyai rata-rata recovery $96,23 \%$ dengan demikian metoda destruksi ini sudah baik karena rata-rata recovery diperoleh 96,23\% yang berada pada nilai kisaran persentase recovery yang disaratkan, yaitu pada rentang $100 \% \pm 15$ dengan nilai yang lebih mendekati $100 \%$. Rentang tersebut dianggap baik karena menunjukan bahwa metoda tersebut mempunyai ketepatan yang baik dalam menunjukan tingkat kesesuaian nilai rata-rata dari suatu pengukuran yang sebanding dengan nilai sebenarnya dapat dikatakan pada proses destruksi tidak ada $\mathrm{Pb}$ yang hilang dan dapat dianggap akurat (Ervina, 2013).

\section{Uji Presisi}

Uji presisi dilakukan dengan metode repitabilitas, yaitu pengulangan dilakukan dalam kondisi yang sama dalam interval waktu yang singkat. Kondisi sama ini dapat diartikan dengan penggunaan laboratorium yang sama, metode analisis yang sama, dan pereaksi serta peralatan yang sama. Metode repitabilitas dianggap lebih efisien karena waktu yang digunakan lebih singkat serta dengan proses lebih mudah. Presisi yang menggambarkan kesalahan acak dari suatu pengukuran dinyatakan dalam bentuk persentase Relative Standard Deviation (\% RSD) (Sumardi, 2002)

Tabel 3. hasil uji presisi Logam Pb Pada Rambut

\begin{tabular}{|c|c|c|c|c|}
\hline \multirow[b]{2}{*}{ Destruksi } & \multicolumn{3}{|c|}{ Konsentrasi $\mu \mathrm{g} / \mathrm{kg}$} & $\% \mathrm{RSD}$ \\
\hline & $\begin{array}{c}I \\
0.6929\end{array}$ & $\begin{array}{c}\text { II } \\
0.6903\end{array}$ & $\begin{array}{c}\text { III } \\
0.6222\end{array}$ & 4.01 \\
\hline
\end{tabular}


Berdasarkan tabel dapat dilihat nilai persentase metode destruksi sebesar $4.01 \%$. nilai yang diperoleh masih berada pada rintangan yang disyaratkan. Konsentrasi $\mathrm{Pb}$ hasil analisis adalah $<5 \%$ sehingga penelitian ini termasuk kedalam kategori trace analysis (Sumardi, 2002).

Uji Limit of Detection (LoD), Limit of Quantitation (LoQ) dan uji Liniearitas

Uji Limit of Letection (LoD) adalah jumlah terkecil analit dalam sampel dapat dideteksi yang masih memberikan respon signifikan dibandingkan dengan blangko. Batas deteksi merupakan parameter uji batas dan batas kuantitasi merupakan parameter pada analisis renik diartikan sebagai kuantitas terkecil analit dalam sampel yang masih dapat memenuhi kriteria cermat dan seksama. Limit of kauntitasi (LoQ) adalah kosentrasi analit terendah dalam sampel yang dapat ditentukan dengan presisi dan akurasi yang dapat diterima pada kondisi operasional metode yang digunakan. LoQ merupakan suatu kompromi antara kosentrasi dengan presisi dan akurasi yang dipersyaratkan. Jika kosentrasi LoQ menurun maka presisi juga menurun. Jika presisi tinggi dipersyaratkan, maka kosentrasi LoQ lebih tinggi harus dilaporkan. LoQ adalah konsentrasi atau jumlah terendah dari analit yang masih dapat ditentukan dan memenuhi kriteria akurasi dan presisi. Limit of Kuantitasi disebut limit pelaporan (Dachriyanus, 2004).

Tabel 4 Uji Limit of Detection (LoD), Limit of Quantitation (LoQ)

\begin{tabular}{cccccc}
\hline No & Konsentrasi $(\mathrm{ppm})$ & Absorban & Yi & Y-Yi & $(\mathrm{Y}-\mathrm{Yi}) 2$ \\
\hline 1 & 0.200 & 0.0082 & -0.01376 & 0.02196 & 0.000482242 \\
2 & 0.400 & 0.0163 & -0.00072 & 0.01702 & 0.00028968 \\
3 & 0.600 & 0.0235 & 0.01232 & 0,01118 & 0.000124992 \\
4 & 0.800 & 0.031 & 0.02536 & 0.00564 & $3.18096 \mathrm{E}-05$ \\
5 & 1.000 & 0.0382 & 0.03840 & -0.0002 & $4 \mathrm{E}-08$ \\
& & Jumlah & & & 0.000928764 \\
& SDX/Y & & & 0.0268 \\
& LOD & & & 0.0804 \\
& & LOQ & & & 0.2680 \\
\hline
\end{tabular}

Berdasarkan tabel 4 hasil perhitungan nilai Limit of Deteksi (LoD) yang merupakan penjumlahan antara nilai rata-rata konsentrasi terkecil ditambah dengan hasil perkalian tiga kali standar deviasi $\mathrm{x} / \mathrm{y}$, sehingga didapatkan limit deteksi sebesar $0.0804 \mathrm{mg} / \mathrm{L}$. Sedangkan hasil perhitungan nilai limit kuantitasai (LoQ) jika konsentrasi LoQ menurun maka presisi juga menurun dengan hasil perkalian sepuluh kali standar deviasi $\mathrm{x} / \mathrm{y}$, sehingga didapatkan limit kuantitasi sebesar $0.2680 \mathrm{mg} / \mathrm{L}$ (Dachriyanus, 2004) 


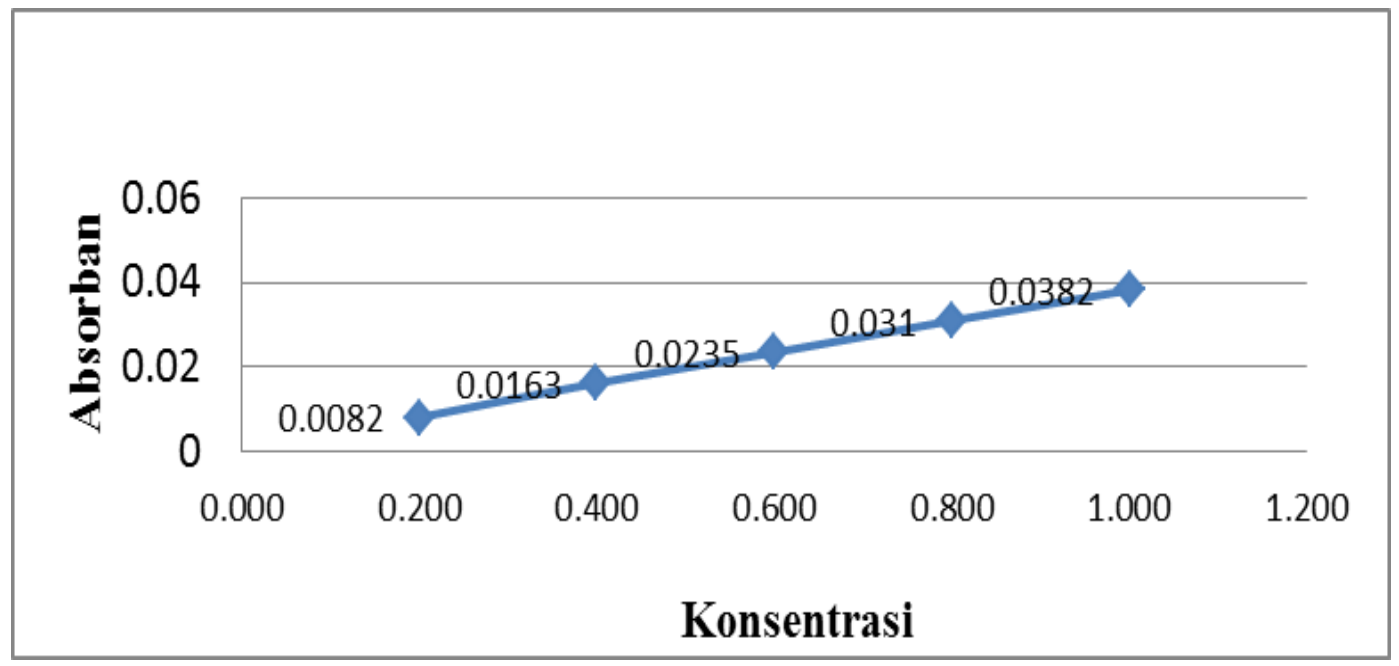

Gambar 2. Kurva kalibrasi larutan standar timbal $(\mathrm{Pb})$

Berdasarkan grafik diatas hasil tersebut dapat dilihat pada gambar kurva kalibrasi larutan standar timbal $(\mathrm{Pb})$ yang menunjukkan titik konsentrasi. Dalam kurva kalibrasi menunjukkan hasil yang linear, namum pengukuran harus mencapai limit kuantitasi agar pengukuran lebih akurat. Dengan demikian sesuai dengan gambar kurva kalibrsi larutan standar timbal, hasil pengukuran metode destruksi dikatakan lebih baik dengan konsentrasi yang melebih LoQ sehingga memberikan hasil dengan akurasi yang tinggi.

\section{KESIMPULAN}

Dari penelitian yang telah dilakukan dapat disimpulkan bahawa lama bekerja mempengaruhi besarnya kandungan logam $\mathrm{Pb}$ yang yang terdapat dalam rambut. Semakin lama bekerja maka semakin besar juga kandungan logam $\mathrm{Pb}$. Jumlah $\mathrm{Pb}$ yang paling banyak terdapat pada masa kerja yang paling lama yaitu $9-12$ tahun dengan kandungan logam $\mathrm{Pb}$ sebanyak $0,8175 \mathrm{mg} / \mathrm{g}$

\section{DAFTAR KEPUSTAKAAN}

Anderson R. 1987. Sample Pretreatment \& Separation. New York. Jonh Willey \& Sons

Dachriyanus. 2004. Analisis Struktur Senyawa Organik Secara Spektroskopi Edisi I. Penerbit Andalas University Press. Padang

Darmono. 1995. Logam dalam Sistem Biologi Makhluk Hidup.Penerbit Universitas Indonesia. Jakarta

Darmono. 1995. Lingkungan Hidup Dan Pencemaran. UI-Press. Jakarta.

Fardiaz S. 1992, Polusi Air dan udara, Kanisius, Yogyakarta.

Hamid RZ. 1991. Dampak Polutan Plumbun (Timbal) terhadap Lingkungan Hidup dan Kesehatan Manusia. Jurnal Lingkungan dan Pembangunan, jakarta.

Harmita. 2004. Petunjuk Pelaksanaan Validasi Metode dan Cara Perhitungannya. Departemen Farmasi FMIPA-UI :Jakarta.

Harvey, David. 2000. Modern Analitycal Chemistry. The McGraw-Hill Companies. USA.

Librawati TP. 2005. Analisis Cemaran Pb pada Bawang Daun (Allium fitstulosum L) di 
daerah Dieng Wonosobo. Universitas Jendral Sudirman: Fakultas Biologi.

Marganof. 2003. potensi limbah udang sebagai penyerap logam berat (timbal, cadmium dan tembaga.jakarta.

Palar H.1994. Pencemaran dan Toksikologi Logam Berat. Jakarta : Rineka Cipta.

Palar H. 2004. Pencemaran dan Toksikologi Logam Berat. Rineka cipta. Jakarta.

Pettrucci RH. 1982. General Chemistry (3 rd ed).New York: Mc. Millan Publishing Co.

Saeni MS. 1997. Penentuan Tingkat Pencemaran Logam Berat dengan Analisis Rambut. Orasi Ilmiah. Bogor

Supriyanto C, Samin, Zainul k. 2007. Analisis cemaran logam berat $\mathrm{Pb}, \mathrm{Cu}$, dan $\mathrm{Cd}$ pada ikan air tawar dengan metode spektrometri nyala serapan atom (SSA). Yogyakarta.

Sukirno \& Murniasih S. 2009. Analisis Unsur $\mathrm{Fe}, \mathrm{Ca}, \mathrm{Ti}, \mathrm{Ba}, \mathrm{Ce}, \mathrm{Zr}$ dan La dalam Sedimen Laut di Semenanjung Muria dengan Metode XRF. Prosiding Pusat Teknologi Akselerator dan Proses Bahan. Jakarta: LIPI

Sumardi. 2002. Validasi Metode Pengujian. Jakarta: Pusat Standardisasi dan Akreditasi Sekretariat Jendral Depertemen Pertanian

Suwirma SS. Thamsil L. 1988. Distribusi Logam Berat $\mathrm{Hg}, \mathrm{Pb}, \mathrm{Cd}, \mathrm{Cr}, \mathrm{Cu}$, dan $\mathrm{Zn}$ dalam Tubuh Ikan. Majalah Batan 